http://jmscr.igmpublication.org/home/

ISSN (e)-2347-176x ISSN (p) 2455-0450

crossref DOI: https://dx.doi.org/10.18535/jmscr/v8i11.45

Journal Of Medical Science And Clinical Research

IGM Publication

An Official Publication of IGM Publication

\title{
Anaesthetic management of a patient with Sick Sinus Syndrome with pacemaker insitu for Urological procedure
}

\author{
Authors \\ Aniruth Geethchand ${ }^{1}$, Hamse Nandinie ${ }^{2}$ \\ ${ }^{1}$ Post Graduate, Department of Anaesthesiology and Critical Care, CHRI \\ ${ }^{2}$ Assistant Professor, Department of Anaesthesiology and Critical Care, CHRI
}

\section{Introduction}

Sick sinus syndrome encompasses a heterogenous group of disturbances of cardiac rhythm related to sinus node dysfunction. The term 'sick sinus' to describe a condition in which chaotic atrial activity followed electrical cardio version. We report a case of 38 year old male with sick sinus syndrome with pacemaker insitu to undergo surgery for right ureteric stone removal.

\section{Case Report}

A 38year old male with complaints of pain in the right loin region, vomiting and burning sensation while urination for three weeks and diagnosed to have right ureteric calculi and planned for right ureteroscopic lithotripsy with double $\mathrm{J}$ stenting. Patient is a known case of sick sinus syndrome with pacemaker insitu on VVI mode for 10 years. $\mathrm{He}$ is a known case of depressive disorder on $\mathrm{T}$. Nexito $10 \mathrm{mg}$ and $\mathrm{T}$. Lonazep $0.5 \mathrm{mg}$ on night. Patient also diagnosed to have Diabetes Mellitus and Dyslipedemia on T. Galvas $50 \mathrm{mg}$, T.Amaryl $\mathrm{Mz}$ and T.Rozuvas 10mg.Patient's coronary angiogram showed slow flow in coronaries and normal epicardial coronary arteries. Basic investigations done and found within normal limits. ECG showed pacemaker rhythm. ECHO showed no regional wall motion abnormalities, PPI insitu, ejection fraction 60 percent and TRPG $21 \mathrm{mmHg}$. Cardiac Opinion sought in view of pacemaker settings prior to surgery and was advised to change the pacemaker settings before surgery with the help of company person. After the consultation patient given fitness under ASA III. Patient pacemaker settings changed with the help of company person and patient shifted to operating room and vitals noted. Under aseptic precautions patient in sitting position using $25 \mathrm{G}$ Quincke needle Spinal Anaesthesia was administered. Patient made supine immediately and oxygen given via facemask at $61 / \mathrm{min}$. After attaining level of T6, lithotomy done. During the procedure the patient Heart Rate (HR) maintained around 60 beats per minute and Mean Arterial Pressure (MAP) maintained above 60 and saturation is about 99 percent. Duration of the procedure lasted for one hour and patient shifted to the recovery room and vitals monitored. Pacemaker settings changed back to VVI mode and ECG taken showed pacemaker rhythm. Postoperative period was uneventful. Patient came for follow up after ten days and was doing well. 


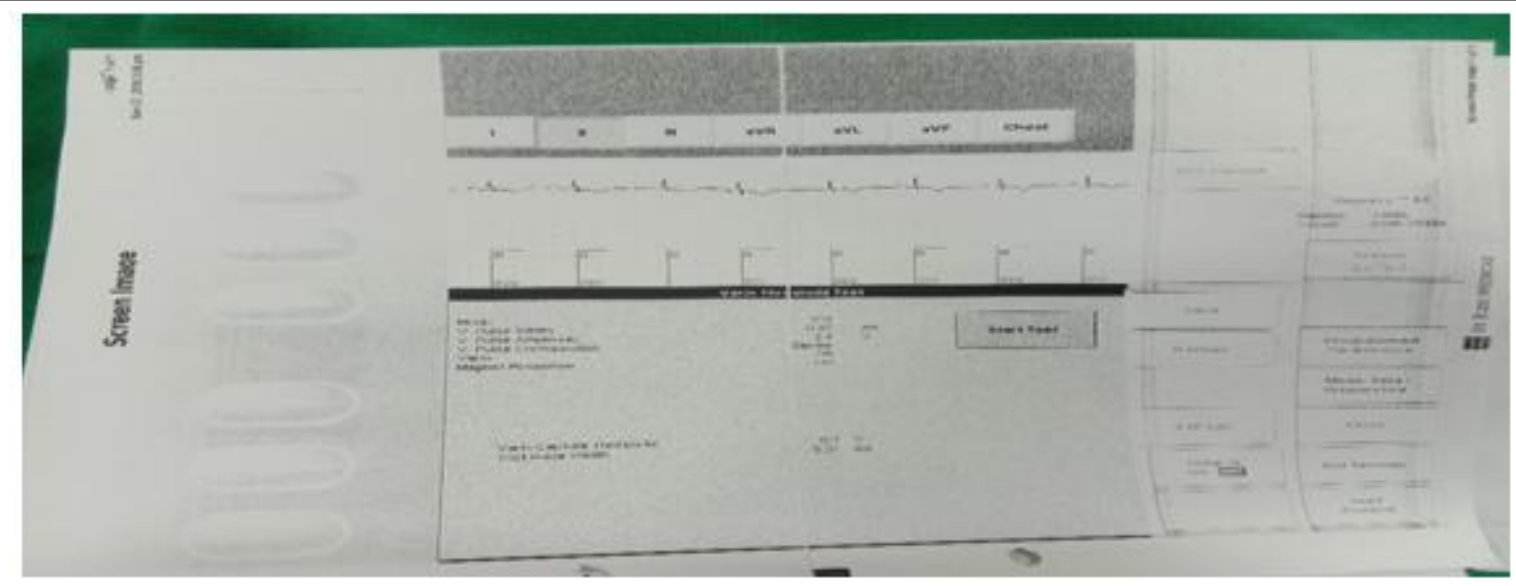

Figure 1-VVI mode

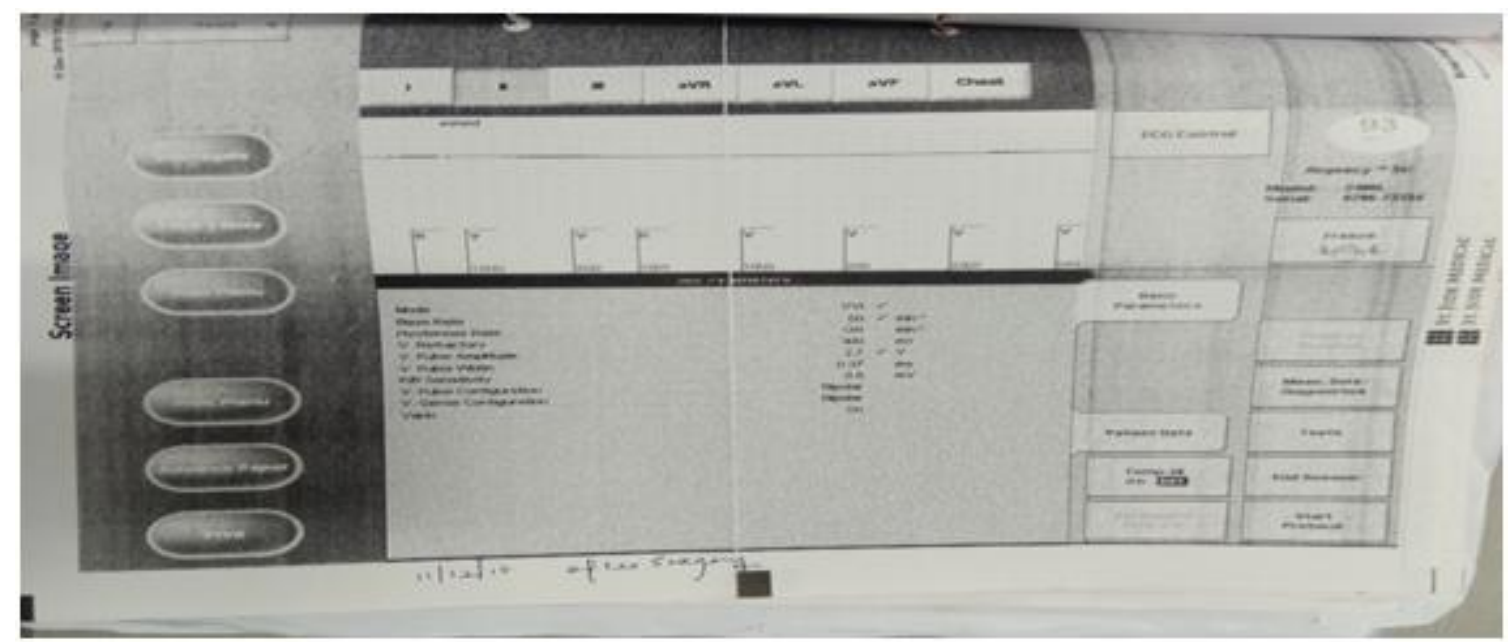

Figure 2-post surgery setting reverted to normal mode

\section{Discussion}

Sick sinus syndrome encompasses a number of sinus nodal abnormalities that includes: persistent spontaneous sinus bradycardia not caused by drugs and inappropriate for physiological circumstances, apparent sinus arrest or exit block, combination of Sino-atrial and atrial-ventricular conduction disturbances and alternation of paroxysm of rapid regular or irregular atrial tachyarrhythmias and periods of slow atrial and ventricular rates. This diversity of sinus node dysfunction is partly a consequence of a dual innervation with both sympathetic and parasympathetic components ${ }^{[1,2]}$.

Sick sinus syndrome more common in males and older age group. It also occurs in young people, when genetic factor is involved ${ }^{[3,4]}$ and in children it occurs after cardiac surgery or along with congenital heart disease or myocarditis ${ }^{[5]}$. The cause remains unknown but some show loss of specialized atrial muscle cells and node is replaced by fibrous tissue. Coronary artery disease does not correlate with sick sinus syndrome, as sinus node artery will not get affected if atherosclerosis occurs along with sick sinus syndrome ${ }^{[6]}$.

Diagnosis of SSS is difficult as most of the times ECG is normal only. A 24-hour ambulatory ECG may show dysrhythmias with normal 12 lead ECG. They do not demonstrate increase in heart rate in strain phase of Valsalva manoeuvre or decrease in post Valsalva blood pressure overshoot. Carotid sinus massage produces decrease in heart rate leads to sinus arrest for 3-6 seconds. Sometimes they may present with syncope, dizziness, palpitations, angina, signs of failure, cerebrovascular accidents ${ }^{[7]}$. 
Most individuals can compensate for reduction in cardiac output due to loss of atrial systole by activation of baroreceptor reflexes that may increase peripheral resistance and maintains systemic blood pressure. ${ }^{[8]}$

The question of pacing arises once sick sinus syndrome has been diagnosed and insertion of a pacemaker does not prolong survival rate but it may improve quality of life. Symptomatic cases must be paced. Patient without a pacing wire who present for surgery with sick sinus syndrome may pose a problem for the anaesthetist, particularly if they have bradycardias thatare unresponsive to chronotropic drugs. ${ }^{[9,15]}$

Generic codes for Pacemakers ${ }^{[10]}$

\begin{tabular}{|l|c|c|c|c|}
\hline I pacing & II sensing & III response & IV programmability & V tachycardia \\
\hline O-none & O-none & O-none & O-none & O-none \\
\hline A-Atrium & A-Atrium & I-inhibited & C-communicating & P-pacing \\
\hline V-Ventricle & V-Ventricle & T-Triggered & P-Simple programmable & S-Shocks \\
\hline D-Dual (A+V) & D-Dual (A+V) & D-Dual(I+T) & M-Multi programmable & D-Dual (P+S) \\
\hline S-Simple (A or V) & Simple (A or V) & & R-Rate modulation & \\
\hline
\end{tabular}

Spinal anaesthesia has cardiovascular effects by sympathetic blockade that extends above the level of sensory block by 2 to 6 segments. Bradycardia and hypotension may occur ${ }^{[11,12]}$. In this condition ephedrine hydrochloride is used as it increases both heart rate and blood pressure at the same time. ${ }^{[13,14]}$. Hence, spinal anaesthesia in patients with SSS can be challenging because patients with sick sinus syndrome are unable to produce a tachycardic response to hypotension, even when sympathetic blockade is not extensive, and that those with enhanced parasympathetic tone are especially prone to bradycardia if the block is high. The diagnosis of SSS may become uncovered during spinal anaesthesia. The occurrence of unexplained bradycardia unresponsive to atropine was the first pointer to the diagnosis in our patient. ${ }^{[15]}$

\section{General Considerations}

Usage of cautery should be careful. Bipolar electrocautery or harmonic scalpel used. Short, intermittent and irregular bursts at lower energy levels are used. The distance between the EMI source and pulse generator should be at least 6 inches apart ${ }^{[16]}$. Anaesthetic agents do not affect pacing thresholds, but there are sequelae as hyperventilation, acid base disorder, volume overloads, MI, blood concentrations of local anaesthetics $^{[17]}$.
Anaesthetic agents have no effect on the function of CIEDs in the perioperative period. However, in patients with bradycardia, avoiding high doses of fentanyl or dexmedetomidine may be prudent to prevent PPM dependence. In patients with long QT syndrome, drugs which cause QT prolongation such as methadone, haloperidol, ondansetron and high doses of inhalation agents are best avoided due to the theoretical risk of polymorphic ventricular tachycardia. ${ }^{[18]}$

Patients with CIEDs are ideally managed in a high dependency recovery environment with continuous monitoring and full resuscitation equipment immediately available. The defibrillator function of an ICD and any rate modulator pacing function which has been suspended needs reactivating by cardiologist after surgery. The device should be checked at the earliest opportunity if a magnet is used to deactivate a CIED intraoperatively. Any adverse incident relating to a CIED in the perioperative period should be addressed by a cardiologist ${ }^{[19]}$.

\section{Conclusion}

Nowadays more patients with pacemaker insitu coming for non-cardiac surgery. It is important to consider indication for insertion, functioning status and mode of functioning been assessed prior to surgery. It is highly recommended to keep the cardiologist standby during the procedure as the pacemaker may go fault. So careful 
preoperative and intra operative preparation make the procedure to go uneventful and timely intervention is needed if required at the time of incidence. These patients should undergo routine monitoring of the pacemaker and checked periodically

\section{References}

1. BRAUNWALD E: Heart Disease, $2^{\text {nd }}$ edition. Philadelphia: WB Saunders, 1984, pp 693-694.

2. HURST JW: The Heart, $6^{\text {th }}$ edition. New York: McGraw-Hill, 1986, pp 449-450.

3. SHAW DB, KEKWICK CA. Potential candidates for pacemakers. Survey of heart block and sinoatrial disorder(sick sinus syndrome). British Medical Journal 1981; 40:99-105.

4. MACKINTOSH AF. Sinoatrial disease in young people. British Heart Journal 1981; 45:62-6.

5. RADFORD DJ, IZUKAWA T. Sick sinus syndrome: symptomatic cases in children. Archives of Disease in Childhood 1975; 50:879-885.

6. ENCELTR, MEISTERSG, FEITOSAGS, FISCHER HA, FRAXKL WS. Appraisal of sinus node artery disease. Circulation 1975: 52: 286-91.

7. MANDELWJ, HAYAKAWA $\mathrm{H}$, ALLENHN, DANZIGR, KERMAIER AI. Assessment of sinus node function in patients with the sick sinus syndrome. Circulation 1972; 46: 761-9.

8. CHIEN WW, FOSTER E, PHILLIPS B, SCHILLER N, GRIFFIN JC. Pacemaker syndrome in a patient with DDD pacemaker for long QT syndrome. Pacing Clin Electrophysiol1991;14: 1209-1212.

9. BURT DER. The sick sinus syndrome. A complication during anaesthesia. Anaesthesia 1982; 37: 1108-11.

10. HAYES DL, ZIPES DP. Cardiac pacemakers and cardioverter-defibrillator. In: Braunwald E, Heart Disease 6th edition, Philadelphia, WB Saunders, 2001; 7775-814.

11. GREENE NM. Area of differential block in spinal anaesthesia with hyperbaric tetracaine. Anesthesiology 1958; 19:45-50.

12. BURM AG, VAN KLEEF JW, GLADINES MP, SPIERDIJK J, BREIMER DD. Plasma concentrations of lidocaine and bupivacaine after subarachnoid administration. Anesthesiolgy 1983; 59:191-5.

13. SEO, K., TAKAYAMA, H., ARAYA, Y., MIURA, K., TANAKA, Y., KOBAYASHI, Y. AND SOMEYA, G. (1996) Electromagnetic Interference of an External Temporary Pacemaker during Maxillofacial and Neck Surgery. Anesthesia Progress, 43, 64-66.

14. LIU, J., YAO, G.E., ZHOU, H.D., JIANG, X.J. AND CHEN, Q. (2013) Prevention of Hemodynamic Instability in Extra-Cranial Carotid Angioplasty and Stenting Using Temporary Transvenous Cardiac Pacemaker. Cell Biochemistry and Biophysics, 65, 275-279.

15. SHAW DB, HOLMAN RR, GOWERS JI. Survival in sinoatrial disorder (sick-sinus syndrome). British Medical Journal 1980; 280:139-41.

16. American Society of Anesthesiologists (2011) Practice Advisory for the Perioperative Management of Patients with Cardiac Implantable Electronic Devices: Pacemakers and Implantable CardioverterDefibrillators: An Updated Report by the American Society of Anesthesiologists Task Force on Perioperative Management of Patients with Cardiac Implantable Electronic Devices. Anesthesiology, 114, 247-261.

17. STONE, M.E., SALTER, B. AND FISCHER, A. (2011) Perioperative Management of Patients with Cardiac Implantable Electronic Devices. British Journal of Anaesthesia, 107, 116-126. 
18. Chakravarthy M, Prabhakumar D, George A. Anaesthetic consideration in patients with cardiac implantable electronic devices scheduled for surgery. Indian $\mathrm{J}$ Anaesth 2017; 61:736-43.

19. Bryant H C,Roberts P R, Diprose P (2016) Perioperative management of patients with cardiac implantable electronic devices, BJA Education, 16 (11): 388-396. 